\title{
COW'S MILK ALLERGY IN INFANCY
}

\author{
BY \\ W. DAVIES \\ Assistant Paediatrician, East Glamorgan Hospital
}

(RECEIVED FOR PUBLICATION OCTOBER 7, 1957)

It appears that, in this country, allergy to cow's milk, manifesting itself in infancy, is still regarded as a rarity. Borman (1953) describes milk sensitivity in infancy as a rare condition and the only case report in the available British literature is that of Brodribb (1944). The purpose of this paper is to present the clinical findings in one infant in whom the diagnosis of milk allergy appears to have been proved and to summarize the features described in the literature.

\section{Case Report}

C.C.L. (No. 29911), a male first infant, whose father had suffered from seasonal allergic rhinitis for several years, was born on January 6,1957 . He was seen on February 2, 1957. After a normal pregnancy he was delivered at full-term, weighing $8 \mathrm{lb} 2 \mathrm{oz}$., and was entirely breast fed up to five days before admission. During this period he had been contented, was feeding well and had apparently gained weight. At this time, his mother decided to change to artificial feeding because her milk supply was diminishing. A half-cream preparation of dried milk was used. Four days later, he became reluctant to take his feeds, vomited frequently and developed a widespread rash. His mother remarked that he looked ill, seemed apathetic and listless, but cried if disturbed or if attempts were made to feed him. His stools, previously formed, now became loose, frequent (six to eight in the previous 24 hours) and were noticed to contain mucus. He was admitted to hospital.

On admission, he weighed $8 \mathrm{lb} .13 \mathrm{oz}$., and showed clinical evidence of mild dehydration with slightly inelastic skin and rather sunken eyes. His whole body was covered with a bright red rash, erythematous on the trunk and limbs and urticarial on the face and scalp, with a tendency, in places, to ring formation. His palms and soles were a uniform bright scarlet colour. A soft systolic bruit was audible to the left of the sternum but no other abnormal physical signs were detected. He was afebrile and his heart-rate was 132 per minute. During the examination he passed a watery, green stool containing a good deal of mucus.

He was then offered feeds of half-strength Hartmann's solution which he took eagerly without vomiting. When seen again 16 hours later, the rash had completely disappeared and he appeared more contented and well hydrated. A provisional clinical diagnosis of cow's milk allergy was then made.

The results of laboratory investigations were as follows: stool cultures on three successive days were negative for the enteric, dysentery and type-specific $E$ coli groups. No pathogenic organisms grew from blood cultures. There was a faint trace of albumin in the urine, but it was free from deposit and on culture was sterile. A radiograph of the chest was clear. A blood count showed haemoglobin, $76 \%$; red blood cells, $3.900,000$ per c.mm.; white blood cells, 15,800 per c.mm.; polymorphs, $38 \%$; eosinophils, $18 \%$; lymphocytes, $41 \%$; and monocytes, $3 \%$. W.R. and Kahn tests on maternal blood were negative.

Stained films prepared from the mucus found in his stools showed large numbers of eosinophil cells. A scratch test using cow's milk produced an immediate urticarial weal, $1.5 \mathrm{~cm}$. in diameter.

After 24 hours on clear fluids, he was offered feeds of expressed breast milk obtained from the breast milk bank at St. David's Hospital, Cardiff. These were taken eagerly without vomiting, his stools became normal and during the first few days he gained $8 \mathrm{oz}$. in weight, and appeared to be a normal contented infant. On February 13 , he was again offered the same preparation of halfcream dried milk and, within a few hours, he became extremely reluctant to take a feed, vomited repeatedly and again passed frequent, loose stools. A faint roseolar rash appeared on his trunk and face and his weight fell to $8 \mathrm{lb} .10 \mathrm{oz}$. Feeds of half-strength Hartmann's solution were again taken quite eagerly.

On February 17 it was decided to restart feeds of expressed breast milk and again, within a few hours, his symptoms had cleared. His subsequent progress was completely satisfactory and on March 7 he weighed $10 \mathrm{lb} .4 \mathrm{oz}$. It was then decided to try the effect of feeding him with a soya-bean preparation known as Soyolk, composed of:

\begin{tabular}{|c|c|c|c|c|}
\hline Fat & 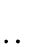 & 20 & Glucose & $\because$ \\
\hline Protein & .. & 41 & Ash & $\cdots$ \\
\hline Carbohydrate & . & $18 \cdot 59$ & Fibre & $\cdots$ \\
\hline Moisture & .. & 7 & Phosphate & $\ddot{x}$ \\
\hline
\end{tabular}

For a few days, these feeds were taken quite well but he gradually began to lose weight, became irritable, vomited occasionally and passed loose, bulky, and offensive stools. On March 14, expressed breast milk feeds were restarted and his weight began to increase 
again. On March 31 he weighed $11 \mathrm{lb} .1 \mathrm{oz}$, , on April 24, $12 \mathrm{lb} .4 \mathrm{oz}$. and on May 19, $13 \mathrm{lb} .5 \mathrm{oz}$.

On April 2, oral hyposensitization to cow's milk was attempted, starting with one drop daily and doubling the dose each day. On April 9 he was taking $1 \mathrm{dr}$. daily and, subsequently, the dose was increased by $1 \mathrm{dr}$. daily. No untoward effects were noted until April 13 when he was taking $5 \mathrm{dr}$. His stools then became rather loose and the dose was not increased until they were more formed on April 25. No further difficulties were encountered and by May 20 he was taking four-hourly feeds, each of $8 \mathrm{oz}$. of cow's milk, without any abnormal symptoms or signs (Fig. 1).

$\mathrm{He}$ has since progressed quite satisfactorily. On September 6, 1957, he weighed 17 lb., was taking cow's milk, rusks and cereals without difficulty. His stools were well-formed and free of mucus. The cow's milk scratch test now produced an area of erythema slightly less than $1 \mathrm{~cm}$. in diameter.

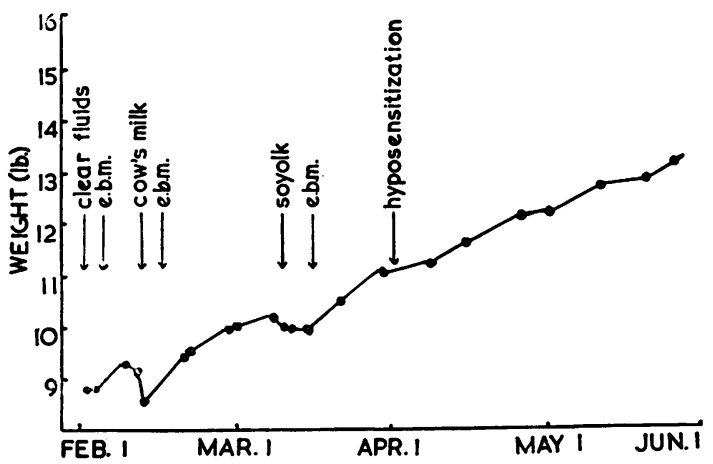

FIG. 1.-Effect of different types of feed on infant C.C.L.'s weight gain.

\section{Discussion}

Diagnosis. The findings in the patient described here seem to leave no doubt as to the correct diagnosis. Collins-Williams (1954) states that where a diagnosis of gastro-intestinal allergy is postulated the following criteria must be satisfied:

(1) The history must be compatible with the diagnosis of allergy. (2) A specific allergen must be determined. (3) Symptoms must appear within a reasonable time after ingestion of the allergen. (4) Symptoms must disappear within a reasonable time after exclusion of the food from the diet. (5) Symptoms must return when the food is reintroduced. (6) The food must be one commonly tolerated without difficulty by most people. (7) The diagnosis must be supported by other allergic manifestations to the same allergen, e.g., urticaria. (8): The diagnosis is supported by other known allergies in the same patient. (9) Positive findings in other diagnostic procedures such as blood and gastro-intestinal eosinophilia, positive radiological findings, gastric or sigmoidoscopic examination, effects of drugs and results of skin tests would be of confirmatory value.

Most authorities stress that the diagnosis is essentially a clinical one and that skin tests are unreliable.

Clein (1954) reports that, in a series of 206 patients sensitive to cow's milk, there were two or more allergic persons in the same family in $\mathbf{1 7 5}$ cases and one allergic parent in 168 cases. Kane (1957) describing 102 patients found a family history of allergy in $80 \%$.

Incidence. Figures obtained from the literature seem to vary considerably. Clein (1951) states that one in 15 infants are allergic to cow's milk in some degree. Collins-Williams (1956) in a series of 3,000 patients aged from birth to 15 years seen in private paediatric practice, but excluding all those referred with possible allergic symptoms, found an incidence of $0.3 \%$. He also quotes other observers as giving figures varying from less than $0.1 \%$ to $7 \%$.

Pathogenesis. Kane (1957) reports that the intestinal tract of a young infant is more permeable to intact protein than that of older children and adults. Collins-Williams (1955) feels that the milksensitive infant falls into one of four categories: he may be sensitized to the factor common to both cow and goat lactalbumin or to the species specific factor of cow lactalbumin alone. With either of these categories there may be sensitization to casein as well. Finally, and much less frequently, he may be sensitized to casein alone. This would explain the well-known observation that some cow's-milk sensitive infants fail to improve on a diet of goat's milk.

Brodribb (1944) felt that the allergen appeared to be either lactalbumin or lactoglobulin. As both occur together in the preparation of dried milk the exact identity seemed to be of little practical importance.

Clein (1954) stressed that the symptoms could be explained on the basis of the usual pathological changes occurring in allergy: oedema of mucous membranes, spasm of smooth muscle and excess mucus secretion.

Tudor (1956) states that unless the child is sensitive to the lactalbumin of cow's milk, goat's milk is not a successful substitute because the casein is identical in cow's milk and goat's milk. It seems, therefore, that any of the proteins occurring in cow's milk may act as the allergen.

Glaser (1956) quotes investigations which seem 
to confirm that, while human and cow lactalbumin are completely species specific, this is not so in the case of animals as closely related as the cow and goat. However, lactalbumin is markedly heat labile since there is a decrease in antigenic reactivity even at $60^{\circ} \mathrm{C}$., which becomes progressively more marked as the temperature is increased. This would explain why evaporated cow's milk, in which the lactalbumin is practically completely denatured by heat is often as satisfactory as goat's milk in the feeding of milksensitive infants. Casein, however, is relatively heat stable, no change being noted in its antigenic activity until the temperature reaches $100^{\circ} \mathrm{C}$. The changes then taking place probably explain why superheated cow's milk is occasionally tolerated by cow's milk sensitive infants.

Symptoms. The age of onset of symptoms varies with the time of starting cow's milk feeding but Clein (1954) reported that symptoms appeared in $82 \%$ during the first four months and in $89 \%$ during the first year of life. The symptoms attributed to milk allergy vary widely and are summarized in Table 1.
Investigations. Laboratory and radiological investigations can only be of confirmatory value in the diagnosis which is essentially a clinical one. Frequently, all such tests are found to be within normal limits.

Treatment. The essential treatment is to remove the offending allergen from the infant's diet and to replace it with a food which provides the necessary basic requirements for adequate growth. Glaser (1956) suggests that in some mild cases boiled or evaporated cow's milk may prove satisfactory; goat's milk is also worthy of trial but, in a high proportion of cases, results are disappointing. He regards human milk as ideal but dismisses it as impracticable because of the difficulty and expense involved in obtaining an adequate supply. The same author has found Nutramigen, a hydrolysed casein preparation, disappointing but agrees that other authorities have had considerable success with it. He also states that it is possible to use a food prepared with strained meat as the protein base.

Various foods prepared from the soya bean have been reported for several years as containing all the

TABLE 1

PERCENTAGE INCIDENCE OF SYMPTOMS ATTRIBUTED IN THE LITERATURE TO COW'S MILK ALLERGY

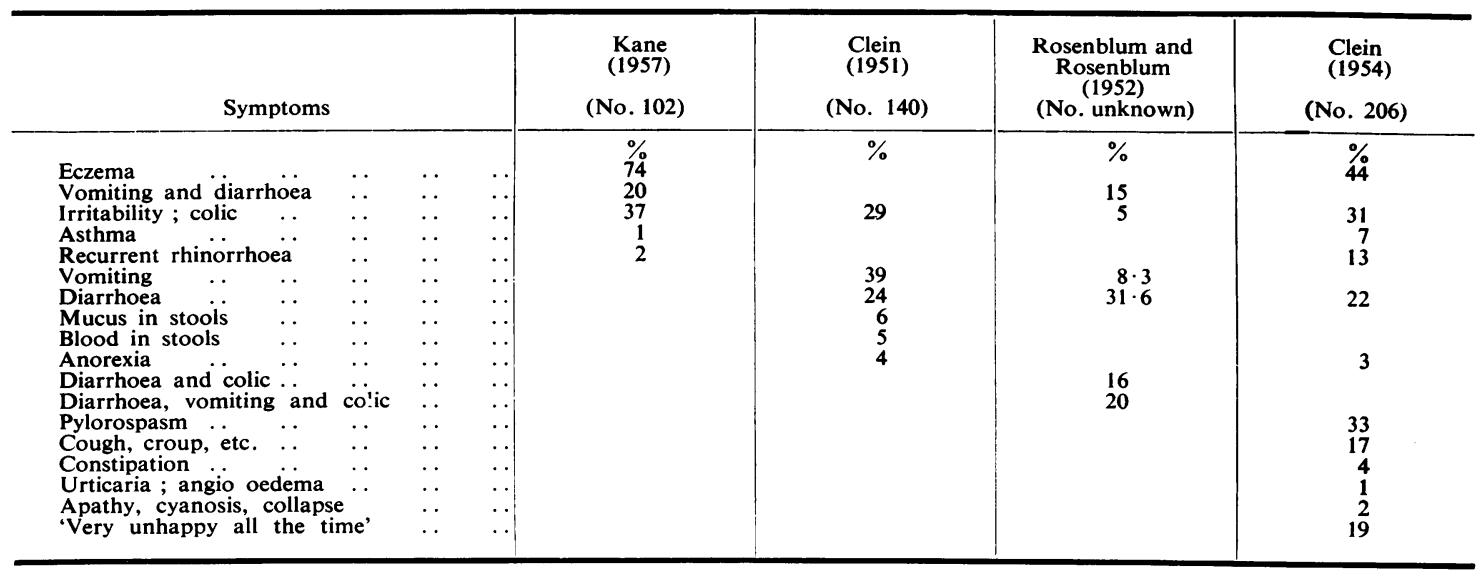

Other clinical features which have been attributed to cow's milk sensitivity include haematemesis, coeliac syndrome, ulcerative colitis, regional enteritis, enuresis, convulsions, headache, migraine and behaviour disturbances.

Bigler (1955) stresses that the picture may vary from a very mild upset to a severe illness and that symptoms may last from a few months up to several years. The infant may become desensitized spontaneously as happens in other forms of allergy. amino-acids necessary for the normal growth and development of the human infant, but recently it has been suggested that they may be slightly deficient in methionine. In our patient, a trial of Soyolk was made but, because of difficulty in feeding and the passage of loose, bulky stools, it was quickly discontinued. Glaser (1956) reports that such symptoms occur frequently for the first few days and suggests that the preparations should be tried at half strength at the beginning. It is possible that persistence 
with this type of feeding might have led to greater success in our patient.

Oral hyposensitization has frequently been reported as being unsatisfactory, but it was a worthwhile and simple procedure in this case.

\section{Conclusions}

Abt (1912) mentioned that some infants have an idiosyncrasy to cow's milk which produces 'toxic symptoms and injuries to the baby'. Since then numerous reports have been published on the subject in foreign literautre but, in this country, the condition is still regarded as a rarity. The patient described here appears to be a fairly obvious example of cow's milk sensitivity; there have been reports of even more acute cases such as infants dying of anaphylactic shock. Although it should be accepted that such acute types are by no means common, a more careful search might well lead to the discovery of the relatively minor forms of the disease. The first essential step in diagnosis is elimination of cow's milk from the diet. This would be simplified considerably if a food similar to Nutramigen were easily available in this country.

\section{Summary}

An example of sensitivity to cow's milk in an infant is described and the available literature summarized. In this patient, replacement of the cow's milk by human milk and subsequent oral hyposensitization produced satisfactory results.

I am grateful to Dr. P. T. Bray and Dr. D. A. Williams for their help and advice in the preparation of this paper.

\section{REFERENCES}

Abt, I. A. (1912). Chicago med. Rec., 34, 115.

Bigler, J. A. (1955). Pediat. Clin. N. Amer., $2,503$.

Brodribb, H. S. (1944). Arch. Dis. Childh., 19, 140.

Clein, N. W. (1951). Ann. Allergy, 9, 195

Clis5). Pediat. Clin. N. Amer., 1, 949.

Collins-Williams, C. (1954). Bull. Hosp. sick Child. Toronto, 3, 68. (1955). Ann. Allergy, 13, 415.

- (1956). J. Pediat., 48, 39

Glaser, J. (1956). Allergy in Childhood. 1st ed., p. 444.

(Amer. Lect. Ser. No. 272). Springfield, Iilinois.

Kane, S. (1957). Amer. Practit., 8, 65.

Norman, A. P. (1953). 'Allergy,' In Moncrieff, A. and Evans, P. (Éditors). Diseases of Children, Garrod, Batten and Thursfield's 5th ed. Vol. 1, p. 856. London.

Rosenblum, A. H. and Rosenblum, P. (1952). Pediatrics, 9, 311.

Tudor, R. B. (1956). J.-Lancet, 76, 245. 